\title{
Acid phosphatase activity in liver macrophage aggregates as a marker for pollution-induced immunomodulation of the non-specific immune response in fish
}

Received: 14 October 2002 / Revised: 4 June 2003 / Accepted: 12 June 2003 / Published online: 23 July 2003 (C) Springer-Verlag and AWI 2003

\begin{abstract}
The activity of acid phosphatase in liver macrophage aggregates (MA-AP) of different fish species was used as a marker for a pollution-induced modulation of the digestive capacity of phagocytes, since functions of the non-specific immune response play a central role in the maintenance of animals' health. Based upon the investigation of more than 900 individual flounders (Platichthys flesus) and mullets (Liza aurata), natural variations, gender-specific differences and pollution-induced alterations in AP activity are demonstrated in this study. MA-AP activity was dependent on temperature and season but, nevertheless, distinctions between differently polluted areas were visible in all sampling campaigns with lowest MA-AP activity in fish from the polluted areas of the German Bight and the Israeli coast of the Mediterranean Sea. For organochlorine contaminants, as well as for mercury and copper, a significant correlation could be observed between residue concentrations in fish tissues and MA-AP activity. In all cases, except mercury which showed a positive correlation, AP activity was suppressed in animals with a high contaminant burden. MA-AP activity turned out to give reliable and consistent results for a quantification of immunomodulation in both fish species.
\end{abstract}

Keywords Immunotoxicity · Fish · Biomarker · Macrophage aggregates $\cdot$ Liver

\section{Introduction}

During the last two decades, scientists have become aware of increased disease prevalence and tumour frequency in fish populations in the German Bight

Communicated by H. von Westernhagen, A. Diamant

K. Broeg $(\bullet)$

Alfred Wegener Institute for Polar and Marine Research, Columbusstrasse, 27568 Bremerhaven, Germany

e-mail: kbroeg@meeresforschung.de

Tel.: +49-471-48311382
(Vethaak 1993; Vethaak and Jol 1996; Dethlefsen et al. 2000). These findings have been discussed in the context of immunomodulative effects of environmental chemicals, especially in coastal and estuarine areas (Sindermann 1996; Grinwis et al. 1998). Thus, there is a demand for reliable tests which are able to reflect the status of immunocompetence in fish.

Innate immune responses play a central role in the maintenance of fish health. They make up the most important early defence system in ectothermic organisms, as specific immune reactions, like antibody production, take at least 4-6 weeks at optimum temperature, and lymphocyte functions are extremely suppressed at low temperatures (Ellis 2001). Immunotoxicological risk assessments have demonstrated that, in mammals, a toxically induced suppression of the innate immune response has stronger effects on an animal's resistance against pathogens than the modulation of specific immunity (Luster et al. 1988). The innate immune system of fish is very similar to the mammalian system, and the detection of immunomodulative effects caused by environmental chemicals may therefore be used as a sentinel for potential harm to higher vertebrates (Zelikoff et al. 1991; Anderson and Zeeman 1995; Luebke et al. 1997).

Within the non-specific immune system, macrophages are located in the first line of defence to fight against invaders, take up foreign material and degrade pathogens and cell debris. They are able to phagocyte invading pathogens in all tissues of the host, to present antigens and release a broad range of immunologically active substances and mediators like reactive oxygen (ROS) and nitrogen species, cytokines and proteases. Thus, they act as a kind of mobile operation group to maintain health and tissue homeostasis of the host.

A lot of laboratory studies have been performed to assess macrophage functions and to analyse the immunotoxicity of single contaminants. However, to monitor biological effects and assess environmental risk of feral populations in the field, these studies are not predictive, due to the complex mixture of contaminants organisms have to deal with in coastal habitats. Most of the 
immunological tests, like phagocytic activity, chemotaxis and release of ROS as measures of immunomodulation, have to be measured using living leukocytes. This is often a problem in routine monitoring programmes, where samples have to be taken immediately on board of research vessels or on the beach near sampling locations.

For that reason, the present study aimed to develop an applicable and reliable test for assessing modulation of the non-specific immune response in fish in situ and under field conditions.

Within the framework of the research project MARS from 1995 to 2000, more than 900 flounders from different polluted areas in the German Wadden Sea and mullets from the Israeli Mediterranean coast were tested for their use as bioindicators, and the digestive activity of lysosomes in macrophage aggregates (MAs) in the liver of these fish was tested for its use as a biomarker of immunomodulation.

Acid phosphatase (AP) is one of the central enzymes in the degradation of phagotised pathogens and may therefore serve as a marker for the ability of macrophages to digest, for instance ingested bacteria and parasites, and thus prevent growth and multiplication of these pathogens in the host (Attwood et al. 1996). Different studies have demonstrated a direct correlation between the virulence of bacteria and the suppression of AP activity in phagocytes (Black et al. 1983). In macrophages with decreased AP activity, an impaired ability to degrade bacteria was demonstrated by Vaddi and Wei (1991). An inhibition of AP in macrophages is therefore of fundamental relevance for the function and effectiveness of non-specific immune responses in fish.

The activity of AP is known to be suppressed in different tissues of aquatic organisms by heavy metals, phenols, herbicides like Basalin (Fluchloralin) and crude oil (Drewa et al. 1979; Dalela et al. 1980; Rashatwar and Ilyas 1983; Gupta 1987; Lakshmi et al. 1991). In earlier studies, we demonstrated a suppression of MA-AP activity in male flounder from polluted areas in the German Bight and in MAs of turbot after exposure to specific organochlorines (Broeg et al. 1999, submitted).

In this study, baseline information about MA-AP activity in the liver of different fish species and its modulation caused by contaminants under field conditions is presented. In addition to histochemical enzyme measurements, residue analysis of organochlorines and heavy metals was performed in individual fish to analyse correlations between contaminant load and modulation of macrophage digestive activity by specific substances.

\section{Methods}

Sampling

Sampling in the North Sea was conducted from summer 1995 to autumn 2000 with the research vessel "Uthörn" of the Biologische Anstalt Helgoland (AWI). Flounders (Platichthys flesus L.) between 18 and $25 \mathrm{~cm}$ were caught at five differently polluted locations. Three of them represented a contamination gradient, with the highest pollution in the mouth of the river Elbe, followed by the outer Eider estuary and Tiefe Rinne near Helgoland [for details of contamination levels see Broeg et al. (2002)]. The two other stations were located in the mouth of the River Eider and in front of the east Fresian island Spiekeroog. Fishing was conducted with a bottom trawl (opening $15 \mathrm{~m}$, mesh width in the cod end $40 \mathrm{~mm}$ stretched mesh). The fishing period (i.e. net on the ground) was limited to $30 \mathrm{~min}$ to keep fishing stress as low as possible. Fish were sorted out immediately and kept in tanks with permanent water flow-through and aeration for up to $6 \mathrm{~h}$ until preparation took place. Mullets from the Israeli Mediterranean coast were sampled at two differently polluted locations, one in the contaminated Haifa Bay and one at less polluted Maagan Michael, in 1999 and 2000. Sampling was conducted by commercial fishermen and fish were kept in basins with aeration for up to $6 \mathrm{~h}$, until preparation took place.

Preparation procedure

Preparation of North Sea flounders took place on board the research vessel. Mullets from the Mediterranean coast were prepared in the laboratory of the Kibbutz Maagan Michael. Upon capture, each fish was measured and examined macroscopically for metazoan parasites. The fish were killed by decapitation and the peritoneal cavity was opened. Then the liver was carefully removed, without damaging the gall bladder, and the sex of the fish was determined. A central part of each liver $\left(0.5 \mathrm{~cm}^{3}\right)$ was quick-frozen in liquid nitrogen for determination of AP activity. After processing, the carcasses were deep frozen for subsequent analysis of heavy metals and analysis of organochlorine residues in muscle or liver tissues.

Processing of liver tissue for enzyme histochemistry

In the laboratory, frozen liver pieces were stacked on aluminium chucks and placed into a cryotome with a cabin temperature of $-25^{\circ} \mathrm{C}$. Cryostat sections $(10 \mu \mathrm{m}$ thickness) were incubated for $15 \mathrm{~min}$ in 7\% polypep (Sigma, St. Louis, Mo.), dissolved in $0.1 \mathrm{M}$ citric buffer, $\mathrm{pH} 4.5$, containing $4 \mathrm{mM}$ naphthol-AS-BI-phosphate as a substrate for AP. After the slides had been washed twice in 3\% $\mathrm{NaCl}$ for $5 \mathrm{~min}$, a diazo-coupling reaction was performed in $0.1 \%$ Fast Violet B salt (Sigma) dissolved in $0.1 \mathrm{M}$ phosphate buffer, $\mathrm{pH}$ 7.4 for $9 \mathrm{~min}$ at room temperature $\left(18^{\circ} \mathrm{C}\right)$. Sections were then washed with running tap water for $10 \mathrm{~min}$ and fixed in Baker's formalin for $15 \mathrm{~min}$. After fixation, the slides were rinsed twice in double distilled water and air-dried. Mounting was performed with Kaiser's glycerol gelatine (Merck, Darmstadt, Germany).

MA morphometrics and enzyme activity were assessed interactively as mean area and mean absorbance of the diazo-product of the AP reaction by computer-assisted image analysis, using an Axioskop light microscope (Zeiss, Göttingen, Germany) with monochromatic light $(580 \mathrm{~nm})$ and a $3 \mathrm{CCD}$ colour video camera connected to a personal computer, as used by Chieco et al. (1994).

\section{Analytical chemistry}

Residue analysis was conducted by three commercial laboratories that had undergone intercalibration exercises (Labor für Rückstandsanalytik Bremen GmbH, Institut für Fischqualität, Bremerhaven, and Handels- und Umweltschutzlaboratorium Dr. Wiertz, Hamburg). Flounder: from the September 1995 and January 1996 campaigns, ten muscle tissue samples per location were analysed for their chlorinated hydrocarbon content. From the April 1997 campaign, liver samples were analysed for standard chlorinated hydrocarbons. Heavy metals (mercury, lead, cadmium and copper) were analysed in muscle tissue from the April 1997 and September 1997 campaigns.

Flounder and mullet: in the second part of the project, in 1999 and 2000 , muscle tissues from ten animals from each of the seven 
locations were analysed for organochlorines and heavy metals during each of the four campaigns.

\section{Results}

\section{North Sea flounder}

Within the time course of 5 years, livers of more than 900 individual flounder were analysed for MA-AP activity. In addition, the mean areas of these aggregates were measured. Aggregates were located in all parts of the liver tissue, often closely connected to bile ducts and blood vessels.

Female flounder showed a significantly higher liver MA-AP activity than male fish, but the difference between the mean values of enzyme activity was relatively low. In contrast, MA-AP activity in juvenile flounder was twice as high as in female and male fish (Fig. 1A). For the mean area, no significant differences were found between male and female flounder but, in

A

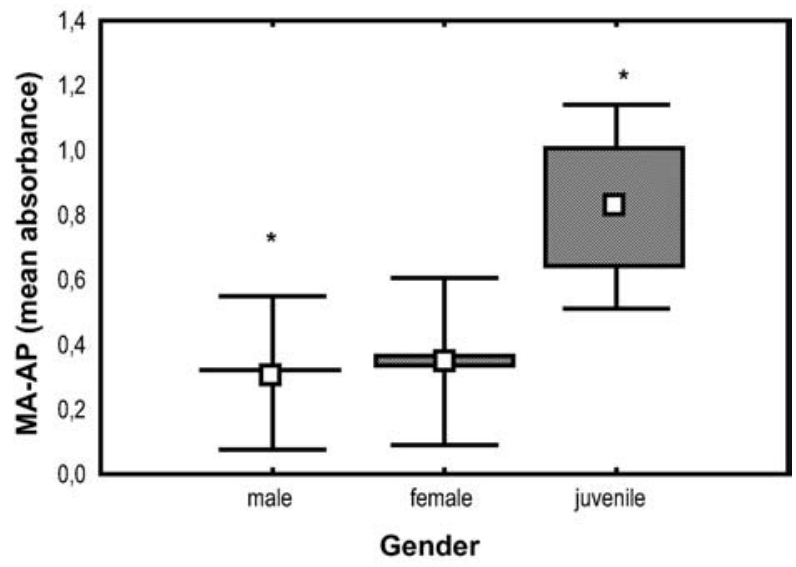

B

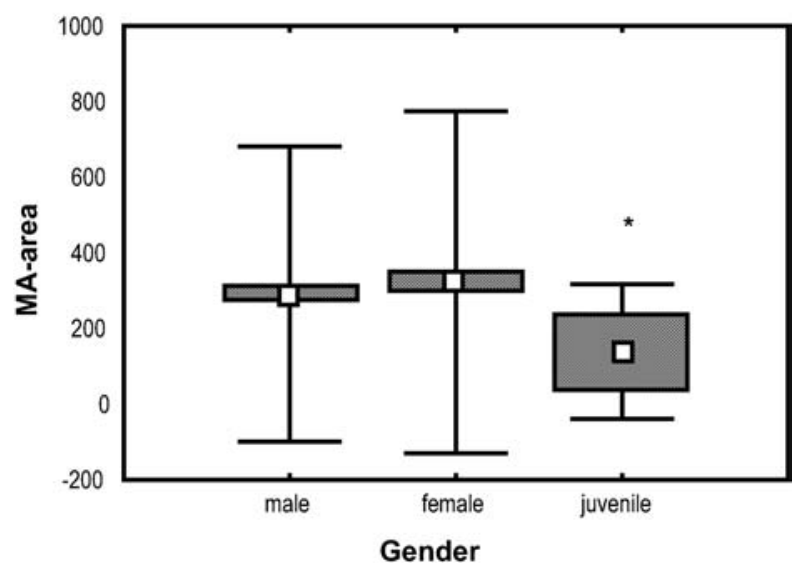

Fig. 1A, B MA-AP activity (A) and MA area (B) in the livers of flounder from the German Bight (white square mean; grey box SE; bar SD). Significant differences between genders and adult/juvenile fish are shown with asterisks (Kruskal-Wallis test, $P<0.05, n=948$ ) juveniles, the mean MA area was half as large as in adult animals (Fig. 1B).

A comparison between female flounder with ripe gonads and females outside the reproductive period showed a significantly lower liver MA-AP activity in reproducing females compared to resting individuals. The mean area of liver MAs in reproducing female flounder was also significantly smaller (Fig. 2). In male flounder, no differences in MA-AP activity or MA size were measured between reproducing and resting fish.

In 1996, samples were taken in all four seasons to analyse differences in MA-AP activity over the timecourse of a year and to analyse the natural variations in liver MA-AP in a feral population under field conditions (Fig. 3). The data were taken from flounder from the less polluted Helgoland location in the period autumn 1995 to autumn 1996. MA-AP activities in winter and spring were very similar and were lower than in the other campaigns. Also, the water temperature was similar in both campaigns. Mean MA-AP absorbance values from the first autumn campaign and the summer campaign ranged between 0.6 and 0.68 . In these campaigns, the water
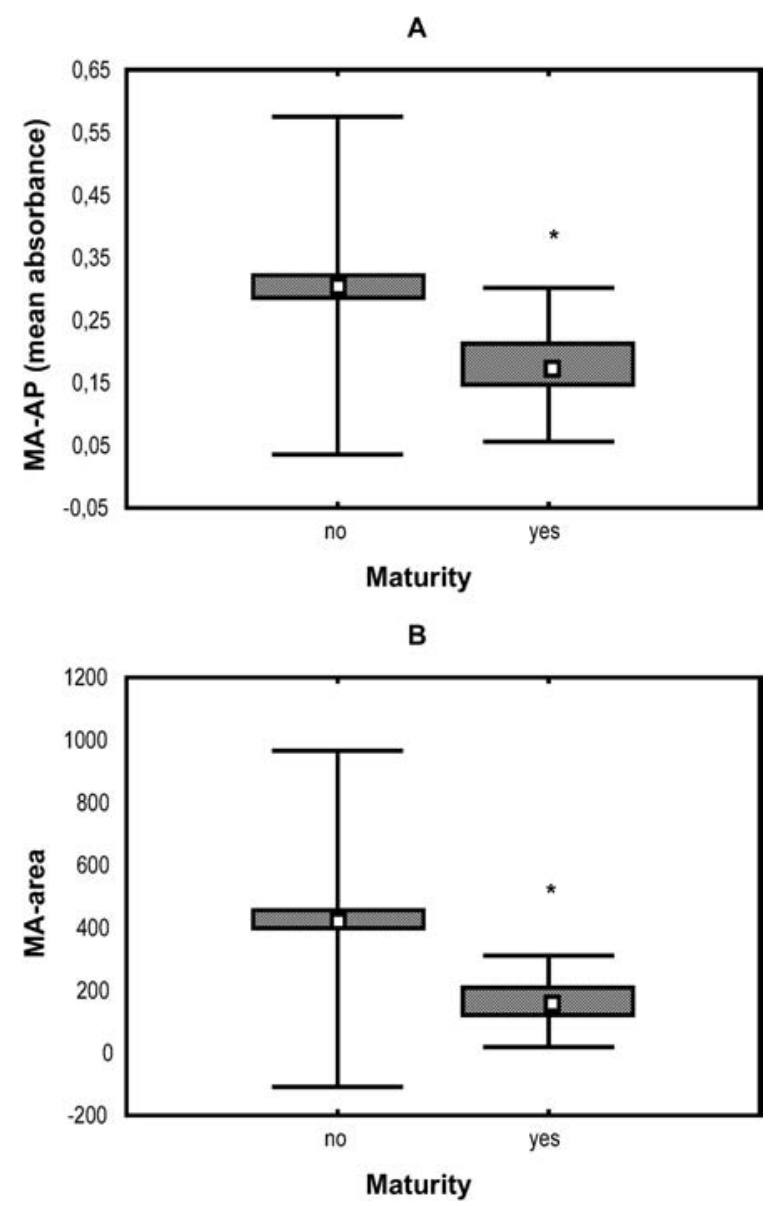

Fig. 2A, B MA-AP activity (A) and MA area (B) in the livers of female flounder from the German Bight (white square mean; grey box SE; bar SD). Significant differences between mature/ripe gonads (yes) and immature (no) fish are shown with an asterisk (Mann-Whitney $U$ test, $P<0.05, n=410$ ) 


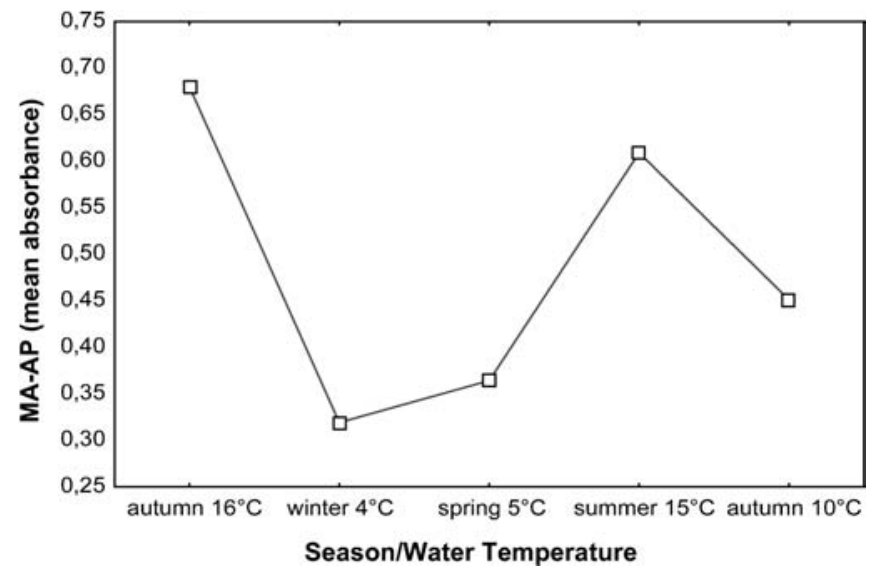

Fig. 3 Mean values of liver MA-AP in flounder from the reference location Helgoland during a time period of 1 year (autumn 1995autumn 1996, $n=100$ )

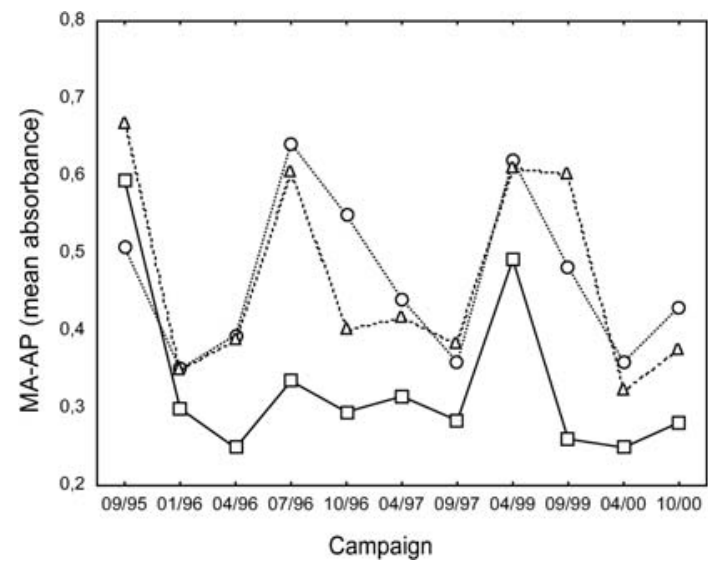

$-0-$ Elbe $\Delta$. Helgoland

Fig. 4 Mean values of MA-AP in livers of male flounder from three locations in the German Bight during the whole project period, $n=467$

temperature was the highest measured $\left(15^{\circ} \mathrm{C} / 16^{\circ} \mathrm{C}\right)$. Lower activities were measured in the second autumn campaign (0.45), when water temperature was lower.

Temporal and spatial differences in MA-AP

The activity of MA-AP in the livers of male flounder from three locations, representing a contamination gradient with the highest pollution in the mouth of the River Elbe, is shown in Fig. 4. In all cases, except in autumn 1995, flounder from the Elbe estuary had lower MA-AP activity than flounder from the other two locations. More detailed results from the first part of the project are presented elsewhere (Broeg et al. 1999). The results shown in Fig. 4 indicate that the temporal variations in MA-AP due to the influence of temperature/seasonality were not masking the differences based on different pollution intensities in the study locations. On the other
Table 1 Spearman's rank correlation of MA area/MA-AP in the livers and organochlorine load in liver tissue of male flounder $(x$ significant, $P<0.05$ and $>0.01 ; x x$ highly significant, $P<0.01$; + positive correlation; - negative correlation)

\begin{tabular}{|c|c|c|c|}
\hline & $n$ & $\begin{array}{l}\text { Significance } \\
(+/-)\end{array}$ & $P$ \\
\hline MA area and $\mathrm{HCB}$ & 7 & $\mathrm{x}(-)$ & 0.010352 \\
\hline MAarea and lindane & 7 & $\mathrm{xx}(-)$ & 0.005621 \\
\hline MA area and dieldrin & 7 & $\mathrm{x}(-)$ & 0.019010 \\
\hline MA area and OCS & 7 & $\mathrm{xx}(-)$ & 0.006102 \\
\hline MA area and $p, p$-DDD & 7 & $\mathrm{xx}(-)$ & 0.008450 \\
\hline MA area and $p, p$-DDE & 7 & $\mathrm{x}(-)$ & 0.016197 \\
\hline MA area and $o, p$-DDT & 7 & $\mathrm{xx}(-)$ & 0.000867 \\
\hline MA area and $p, p$-DDT & 7 & & 0.067635 \\
\hline MA area and PCB 28 & 7 & & 0.101920 \\
\hline MA area and PCB 52 & 7 & $\mathrm{x}(-)$ & 0.010352 \\
\hline MA area and PCB 101 & 7 & x (-) & 0.048905 \\
\hline MA area and PCB 138 & 7 & & 0.175382 \\
\hline MA area and PCB 153 & 7 & & 0.067635 \\
\hline MA area and PCB 180 & 7 & & 0.175382 \\
\hline MA-AP and HCB & 7 & x (-) & 0.010352 \\
\hline MA-AP and lindane & 7 & $\mathrm{xx}(-)$ & 0.005621 \\
\hline MA-AP and dieldrin & 7 & $\mathrm{x}(-)$ & 0.019010 \\
\hline MA-AP and OCS & 7 & $\mathrm{xx}(-)$ & 0.006102 \\
\hline MA-AP and $p, p$-DDD & 7 & $\mathrm{xx}(-)$ & 0.008450 \\
\hline MA-AP and $p, p$-DDE & 7 & $\mathrm{x}(-)$ & 0.016197 \\
\hline MA-AP and $o, p$-DDT & 7 & $\mathrm{xx}(-)$ & 0.000867 \\
\hline MA-AP and $p, p$-DDT & 7 & & 0.067635 \\
\hline MA-AP and PCB 28 & 7 & & 0.101920 \\
\hline MA-AP and PCB 52 & 7 & x (-) & 0.010352 \\
\hline MA-AP and PCB 101 & 7 & x (-) & 0.048905 \\
\hline MA-AP and PCB 138 & 7 & & 0.175382 \\
\hline MA-AP and PCB 153 & 7 & & 0.067635 \\
\hline MA-AP and PCB 180 & 7 & & 0.175382 \\
\hline
\end{tabular}

hand, only MA-AP data obtained from the same season could be directly compared.

Liver MA-AP correlation with contaminant load in flounder

The most obvious correlation between MA-AP activity and residues of contaminants in the flounder was found when the concentration of organochlorines was analysed in liver tissue of the fish. The findings clearly demonstrate that there are differences between male and female fish, not only in the total MA-AP activity, but also in the correlation between residue analysis and MA-AP activity. Considering both genders together, no correlation was observed between organochlorine concentration and MAAP activity in the livers. MA-AP activity in male fish, in contrast, showed a significant negative correlation with the concentration of all analysed organochlorines except PCB 28, 138, 153, 180 and $p, p$-DDT (Table 1). For all organochlorines, a negative correlation between concentration and the size of liver MAs was observed. In all cases, except PCB 28, 138, 153, 180 and p,p-DDT, this correlation was statistically significant.

A completely different result was obtained from female flounder. A negative correlation between organochlorine concentration in the livers and MA-AP was never 
Table 2 Spearman's rank correlation of MA area/MA-AP in the liver and organochlorine load in muscle tissue of flounder $(x$ significant, $P<0.05$ and $>0.01 ; x x$ highly significant, $P<0.01$; + positive correlation; - negative correlation)

\begin{tabular}{|c|c|c|c|}
\hline & $n$ & $\begin{array}{l}\text { Significance } \\
(+/-)\end{array}$ & $P$ \\
\hline MA area and $\mathrm{HCB}$ & 231 & & 0.069776 \\
\hline MA area and lindane & 231 & & 0.835806 \\
\hline MA area and dieldrin & 231 & & 0.712065 \\
\hline MA area and OCS & 231 & & 0.918661 \\
\hline MA area and $p, p$-DDD & 231 & & 0.233870 \\
\hline MA area and $p, p$-DDE & 231 & & 0.348886 \\
\hline MA area and $o, p$-DDT & 231 & & 0.154775 \\
\hline MA area and $p, p$-DDT & 231 & $\mathrm{x}(+)$ & 0.046123 \\
\hline MA area and PCB 28 & 231 & & 0.170258 \\
\hline MA area and PCB 52 & 231 & $\mathrm{x}(+)$ & 0.029920 \\
\hline MA area and PCB 101 & 231 & & 0.067872 \\
\hline MA area and PCB 138 & 231 & $\mathrm{x}(+)$ & 0.017741 \\
\hline MA area and PCB 153 & 231 & $\mathrm{x}(+)$ & 0.027532 \\
\hline MA area and PCB 180 & 221 & & 0.054467 \\
\hline MA-AP and HCB & 231 & x (-) & 0.039756 \\
\hline MA-AP and lindane & 231 & & 0.246742 \\
\hline MA-AP and dieldrin & 231 & $\mathrm{x}(+)$ & 0.024528 \\
\hline MA-AP and OCS & 231 & $x(-)$ & 0.013119 \\
\hline MA-AP and $p, p$-DDD & 231 & $\mathrm{xx}(-)$ & 0.008517 \\
\hline MA-AP and $p, p$-DDE & 231 & $\mathrm{xx}(-)$ & 0.006591 \\
\hline MA-AP and $o, p$-DDT & 231 & $\mathrm{xx}(-)$ & 0.003718 \\
\hline MA-AP and $p, p$-DDT & 231 & $\mathrm{x}(-)$ & 0.022770 \\
\hline MA-AP and PCB 28 & 231 & & 0.397788 \\
\hline MA-AP and PCB 52 & 231 & $\mathrm{xx}(-)$ & 0.007993 \\
\hline MA-AP and PCB 101 & 231 & $\mathrm{xx}(-)$ & 0.001002 \\
\hline MA-AP and PCB 138 & 231 & & 0.560877 \\
\hline MA-AP and PCB 153 & 231 & & 0.562780 \\
\hline MA-AP and PCB 180 & 221 & & 0.058822 \\
\hline
\end{tabular}

Table 3 Spearman's rank correlation of MA area/MA-AP in the liver and heavy metal load in muscle tissue of flounder $(x$ significant, $P<0.05$ and $>0.01 ; x x$ highly significant, $P<0.01$; + positive correlation; - negative correlation)

\begin{tabular}{llll}
\hline & $n$ & Significance $(+/-)$ & $P$ \\
\hline MA area and $\mathrm{Hg}$ & 193 & $\mathrm{x}(+)$ & 0.010074 \\
MA-AP and $\mathrm{Hg}$ & 193 & $\mathrm{xx}(+)$ & 0.000000 \\
MA-AP and Cu & 202 & $\mathrm{xx} \mathrm{(-)}$ & 0.000016 \\
\hline
\end{tabular}

observed. For PCB 28, a positive correlation, which was statistically significant, was measured.

The correlation between organochlorine residues in the muscles of flounder and MA-AP activity, in contrast, was nearly the same for both genders. Muscle tissue analysis of 231 individual flounder of both sexes supported the findings of the analysis of the seven male livers demonstrated above: for all organochlorines except lindane and PCB 28, 138, 153 and 180, the negative correlation between chlorinated hydrocarbons and MA-AP was statistically significant. For dieldrin, the correlation was significantly positive (Table 2 ).

In contrast to the negative links between liver residues and MA area, only positive correlations were observed between organochlorine concentrations in muscle tissue and MA area (PCB 52, 135, 153, Table 2).

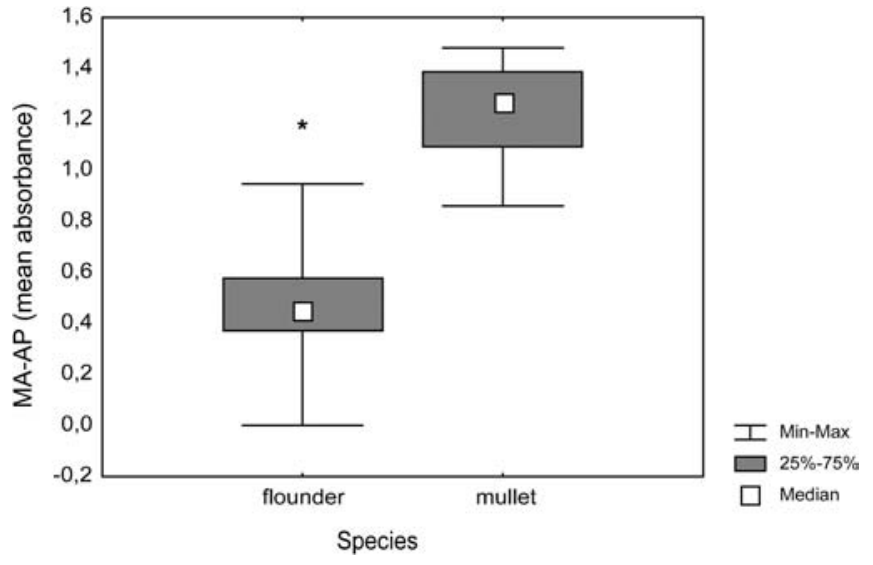

Fig. 5 MA-AP activities in the liver of the two fish species in the reference locations Helgoland and Maagan Michael in autumn 1999 (mean and SD). An asterisk shows significant differences (MannWhitney $U$ test, $P<0.05, n=40$ )

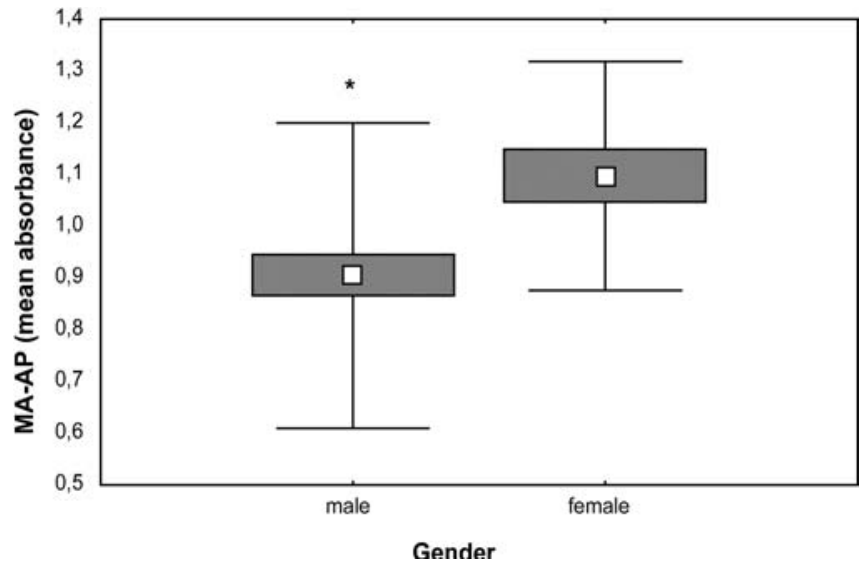

Fig. 6 Gender-specific differences in MA-AP in the livers of mullet from the Mediterranean Sea (mean and SD). An asterisk shows significant differences (Mann Whitney $U$ test, $P<0.05$, $n=110$ )

Mercury and copper residues in muscle tissue of flounder showed the most distinct correlation with MAAP of all the heavy metals analysed (Table 3). The correlations were even more distinct than for organochlorine residues. The concentrations of both heavy metals displayed a highly significant correlation with MA-AP. Mercury was positively correlated, copper negatively.

\section{Mediterranean Sea/mullets}

MAs were more frequently distributed in the livers of mullets than in flounder liver. In addition, the activity of AP was significantly higher. Fig. 5 demonstrates the differences in MA-AP activity between the two fish species in the respective reference locations Helgoland and Maagan Michael in autumn 1999. 


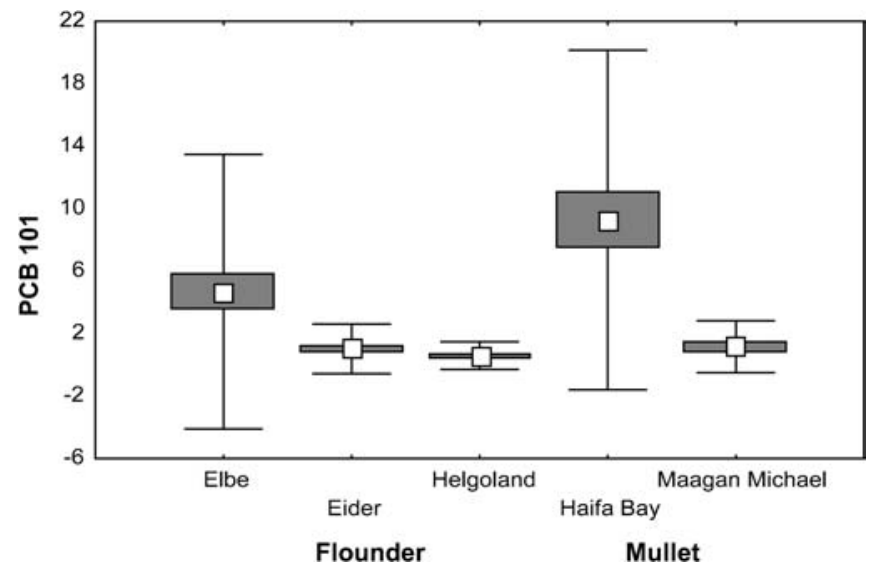

Fig. 7 PCB 101 concentrations ( $\mu \mathrm{g} / \mathrm{kg}$ wet weight) in muscle tissue of flounder and mullet from the five sampled locations in autumn 1999 (mean and SD, $n=50$ )

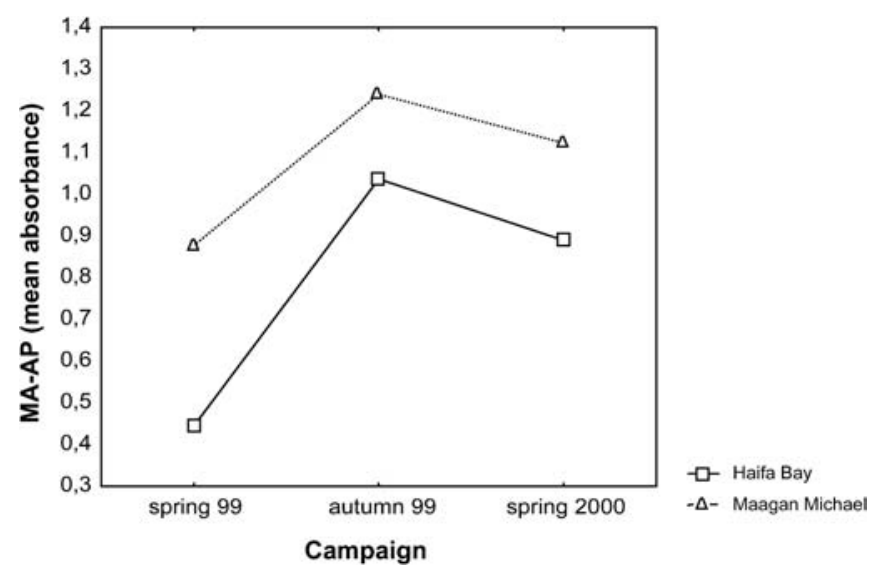

Fig. 8 Mean values of MA-AP in livers of mullets from two locations in the Mediterranean Sea (three campaigns, $n=110$ )

Like in flounder, a significantly higher AP activity was measured in MAs of female mullets, than in those of male mullets (Fig. 6).

The concentrations of PCB 101 in muscle tissue of mullets and flounder from all locations are shown in Fig. 7. For all organochlorine residues measured in 1999 and 2000, highest concentrations were measured in muscle tissue of mullets caught in Haifa Bay.

\section{Temporal and spatial differences of MA-AP}

Within a time period of 2 years, three samplings had been conducted in the Mediterranean Sea: two spring samplings and one autumn sampling. In all three sampling campaigns, mullets from Haifa Bay had significantly lower MA-AP activity in the livers than the fish from the reference location Maagan Michael (Fig. 8).
Table 4 Spearman's rank correlation of MA area/MA-AP in the liver and organochlorine load in muscle tissue of mullets $(x$ significant, $P<0.05$ and $>0.01 ; x x$ highly significant, $P<0.01$; + positive correlation; - negative correlation)

\begin{tabular}{|c|c|c|c|}
\hline & $n$ & $\begin{array}{l}\text { Significance } \\
(+/-)\end{array}$ & $P$ \\
\hline MA area and $\mathrm{HCB}$ & 57 & $\mathrm{x}(-)$ & 0.042342 \\
\hline MA area and $\gamma-\mathrm{HCH}$ & 19 & & 0.817932 \\
\hline MA area and $p, p$-DDE & 57 & $\mathrm{xx}(-)$ & 0.005307 \\
\hline MA area and $p, p$-DDD & 57 & $\mathrm{xx}(-)$ & 0.003486 \\
\hline MA area and $p, p$-DDT & 57 & & 0.105326 \\
\hline MA area and $o, p$-DDE & 17 & & 0.227623 \\
\hline MA area and $o, p$-DDD & 19 & $\mathrm{xx}(-)$ & 0.000435 \\
\hline MA area and OCS & 57 & $\mathrm{x}(-)$ & 0.010645 \\
\hline MA area and dieldrin & 57 & & 0.074475 \\
\hline MA area and PCB 28 & 24 & & 0.133373 \\
\hline MA area and PCB 52 & 26 & & 0.217804 \\
\hline MA area and PCB 101 & 46 & & 0.359924 \\
\hline MA area and PCB 118 & 48 & & 0.198955 \\
\hline MA area and PCB 138 & 57 & $\mathrm{x}(-)$ & 0.028362 \\
\hline MA area and PCB 153 & 57 & $\mathrm{x}(-)$ & 0.031283 \\
\hline MA area and PCB 180 & 57 & $\mathrm{x}(-)$ & 0.027347 \\
\hline MA-AP and HCB & 57 & $\mathrm{xx}(-)$ & 0.002116 \\
\hline MA-AP and lindane & 19 & $\mathrm{xx}(-)$ & 0.001434 \\
\hline MA-AP and $p, p$-DDE & 57 & & 0.852471 \\
\hline MA-AP and $p, p$-DDD & 57 & & 0.087535 \\
\hline MA-AP and $p, p$-DDT & 57 & & 0.424309 \\
\hline MA-AP and $o, p$-DDE & 17 & & 0.056851 \\
\hline MA-AP and $o, p$-DDD & 19 & $\mathrm{x}(-)$ & 0.034532 \\
\hline MA-AP and OCS & 57 & $\mathrm{x}(-)$ & 0.038875 \\
\hline MA-AP and dieldrin & 57 & & 0.378238 \\
\hline MA-AP and PCB 28 & 24 & $\mathrm{x}(-)$ & 0.024805 \\
\hline MA-AP and PCB 52 & 26 & $\mathrm{x}(-)$ & 0.026395 \\
\hline MA-AP and PCB 101 & 46 & $\mathrm{x}(-)$ & 0.030767 \\
\hline MA-AP and PCB 118 & 48 & & 0.080433 \\
\hline MA-AP and PCB 138 & 57 & & 0.196920 \\
\hline MA-AP and PCB 153 & 57 & & 0.258920 \\
\hline MA-AP and PCB 180 & 57 & & 0.196757 \\
\hline
\end{tabular}

Liver MA-AP correlation with contaminant load in mullets

All correlations between the concentrations of organochlorines in muscle tissue and MA-AP in the liver of mullets were negative. These findings correspond to those obtained from flounder from the North Sea. For $\mathrm{HCB}$, lindane, DDD, OCS, PCB 28, 52, 110, these correlations were statistically significant (Table 4). The mean area of MA was also, in most cases, negatively correlated with organochlorine load of the muscle tissue, with the exception of lindane. For HCB, DDE, DDD, OCS, PCB 138, 153, 180, a statistically significant negative correlation was found. This corresponds to the observations from flounder, when the residues in liver tissue were analysed.

For heavy metal residues in mullet muscle tissue, a correlation to MA-AP activity was only observed for copper and this correlation was significantly positive. This finding contrasts with the correlation obtained from North Sea flounder, where a highly significant negative correlation was demonstrated. This finding will be discussed in more detail in the next section. 


\section{Discussion}

A broad range of chemicals is known to modulate the innate immune system of fish, including heavy metals (reviewed by Zelikoff 1993), bleached mill effluents (Aaltonen et al. 2000), chlorothalonil (Baier-Anderson and Anderson 2000), PCBs and HCH (Sweet 1999), to name just a few. In most of the cases, functions of macrophages and/or granulocytes were tested on isolated cells in specific experiments. On the other hand, several field studies have been performed during the last 20 years, trying to use MAs as sentinels for immunomodulation caused by anthropogenic impact (reviewed by Bols et al. 2001). Those studies concentrated on changes in morphology and/or numbers of MAs in kidney, spleen and liver of different fish species, and the results of these studies have been controversial. In contrast, the present study applies to both morphometrical and functional aspects. Earlier exposure experiments performed on turbot in our laboratory indicated that AP activity in MAs may serve as an indicator for immunosuppression caused by organochlorine pesticides (Broeg et al., submitted). The present study presents the outcome of a field study analysing MA-AP and MA area in North Sea flounder and Mediterranean Sea mullet.

To interpret and estimate MA-AP activity differences in animals of differently polluted areas, basic information about the variability of MA-AP activity in fish liver had to be assessed.

AP activity in liver MAs of flounder displayed seasonal changes with highest activities in summer or warm autumns and lowest in winter. Also, in mullets from the Mediterranean Sea reference location, different activities were measured in spring and autumn campaigns. For that reason, direct comparisons of MA-AP activity as a tool for immunomodulation may only be undertaken between samples from the same seasons.

Immunosuppression of humoral and cellular immune response at low temperature has already been observed in different fish species (Bly and Clem 1992; Zapata et al. 1992) and is discussed as the cause of several fish diseases which occur during the winter (summarised in Bly and Clem 1991; Hayman et al. 1992; Crespo et al. 1994; Tort et al. 1998). In rainbow trout, the production of macrophage activating factors by leukocytes has been shown to decrease at low temperature (Hardie et al. 1994). Studies on channel catfish have shown that phagocytosis of anterior kidney cells is not affected at low temperature, but the generation of ROS, the respiratory burst, is (Chen and Ainsworth 1991).

To our knowledge, the present study is the first one to demonstrate a temperature-dependent suppression of the digestive activity of liver MAs in feral fish. Earlier experiments in our laboratory showed a strong positive correlation between the respiratory burst intensity and the activity of AP in liver MAs of turbot (Broeg et al. 2002, submitted).

Despite the seasonal differences in MA-AP activity observed in the present study, both fish species displayed lower activities in areas of high pollution (Elbe, Haifa Bay), when compared to the respective reference, in nearly every sampling campaign. Studies by Fatima et al. (2001) on the effects of paper and pulp mill effluents on Channa punctatus plaque-forming cells found a temperature-dependent suppression of this humoral immune response. Nevertheless, the effect of effluent was stronger than the temperature effect. In summer, when the immune response activity was higher, suppression caused by contaminants was clearer. The same findings were observed in this present study: in the winter campaign, MA-AP activities were very low at all stations but in the summer, when activities were high in animals from Eider and Helgoland, MA-AP activity in Elbe flounder remained at a low level.

In both fish species, a higher MA-AP activity was measured in female fish than in males. The first evidence for a different immune response activity in male and female animals was in dogs: a higher prevalence of helminth parasites was found in male dogs. Male chicken displayed a 19 times higher Ascaridia infestation. Not much information is available about gender specific differences in immune responses in fish. As shown in this study, mean MA-AP activity values are similar in both genders but, nevertheless, significantly different. Although the capacity of specific immune responses of juvenile fish is thought to be limited (Tatner and Manning 1985) the difference in MA area and MA-AP activity between juvenile and adult fish was more distinct. Juvenile fish are therefore meant to rely on non-specific defence mechanisms (Fletcher 1982).

A decreased MA-AP activity was observed in reproducing female flounder. Changes in humoral and cellular immune responses during reproduction have also been described by Alcorn et al. (2002) in sockeye salmon (Onchorhynchus nerka). Complement activity and lymphocyte numbers were dramatically decreased. These findings indicate a potential health hazard for reproducing female fish. The fact that flounder reproduction in the North Sea occurs during the winter, when low temperatures also suppress the immune response, may in addition intensify this risk for reproducing fish. This period may therefore be the most sensitive for animals which are affected by immunosuppressing contaminants. In the present study, low temperatures in the second and third campaign led to an extreme suppression of MA-AP, especially in flounder from the polluted Elbe estuary. The decreased food supply may also influence the activity of MAs in the liver of flounder during reproduction in winter.

\section{MA-AP correlation with organochlorines}

Polychlorinated biphenyls (PCBs) are the most abundant and most widespread class of persistent organic pollutants (Goerke and Weber 2001) and are therefore potentially harmful to the health of aquatic organisms all over the world. The same applies for DDT and its metabolites 
DDD and DDE. PCBs are highly accumulating in fish and have a long half-life. The analysis of these compounds in muscle tissue may therefore be used as background information about the contaminant situation in the framework of the assessment of biological effects in individual organisms. Although there is a strong intercorrelation between PCB congeners, the present study demonstrated differences in the immunomodulative effects caused by single metabolites. For the MA-AP, the highest suppressive effects could be observed with PCBs 52 and 101 in flounder and mullet. In mullet, PCB 28 also caused an inhibition of MA-AP. PCB 52 and PCB 101 belong to the PCB class with unsubstituted carbon atoms in the $m, p$ positions and are not readily eliminated from any fish species (Guiney et al. 1979; Niimi and Oliver 1983; Goerke and Weber 2001). This might be one reason for the clear correlation between MA-AP activity and these congeners in both fish species.

Two other substances that show clear effects on nonspecific immune response in flounder, as well as in mullet, were HCB and OCS.

Sex differences were observed in the MA-AP correlation with organochlorine concentrations, measured in the liver of flounder. In male flounder, a significant negative correlation was found between organochlorine load and MA-AP activity: in females only PCB 28 showed a positive correlation with MA-AP.

These liver samples for organochlorine analysis were taken in April, after the reproduction period. Female flounder mobilise lipophilic contaminants in the liver during egg production (von Westernhagen et al. 1995). During that time, concentrations of lipophilic contaminants in female liver are therefore relatively low. This may be the explanation for the fact that, in the present study, no correlation was found between liver organochlorine concentration and MA-AP. Another explanation is the close connection between non-specific immune response and reproduction in female fish. As is also shown in this study, MA-AP activity in female flounder is lower during reproduction than outside the reproduction period. Thus, a strong influence of endocrinology on nonspecific immune response, especially in female fish, can be assumed.

The strongest suppressive effect on flounder MA-AP activity was demonstrated with copper. Studies on the liver of Heteropneustes fossilis also showed a suppression of ATP and ATPase, induced by copper and cadmium (Gupta and Rajbanshi 1985).

In the present study, contradictory results were obtained from the two fish species concerning the correlation of MA-AP activity and copper residues. The cause of that observation might be that some of the analysed mullet had Myxobolus sp. liver infections. Exposure to copper led to a significant suppression of nitric oxide synthetase (NOS) in macrophages from liver and the bile ducts of mullet (Broeg, personal observation). This inhibition might have led to an increased infection with Myxobolus, accompanied by high MA-AP activity. Excluding the infected mullet resulted in a negative correlation between copper and MA-AP, but this correlation was not statistically significant. The positive correlation between copper residues and MA-AP when all mullets (infected and uninfected) are analysed is therefore probably caused by a second origin: the suppressed NOS.

Basic studies on AP in fish tissue have been performed by Panara (1997) in the northern pike, Esox lucius. Structure and function, as well as the amount, of this enzyme are similar to mammals. For that reason, a comparison of AP activities between lower and higher vertebrate classes might be possible. High activity was found in the spleen of E. lucius, the main location of macrophages in this fish species.

AP activity has been shown to be suppressed by a broad range of different chemicals. A suppression of this enzyme cannot, therefore, be considered as a response to a specific toxic compound but gives a more general indication of immunomodulation. Overall, however, a general suppression of the digestive activity of macrophages might be fatal for the host. The destabilisation of lysosomal membranes, a well-known marker of nonspecific toxic response, is discussed as one cause for the suppression of MA-AP (Lakshmi et al. 1991). Membrane damage at an early stage of exposure may lead to a decreased ability of the cell to maintain the low $\mathrm{pH}$ within lysosomes, which is necessary for optimal enzyme activity.

MA area, in contrast to MA-AP activity, gave controversial results concerning the correlation with organochlorine chemicals. Firstly, we obtained a different correlation, positive and negative, between organochlorine concentration and MA area dependent on the tissue that had been analysed for organochlorines: muscle or liver. Secondly, we obtained a different correlation, positive and negative, depending on the fish species and location: flounder from the North Sea or mullet from the Mediterranean Sea.

From all the analysed locations, mullet from the Mediterranean Sea, especially from Haifa Bay, had the highest concentrations of organochlorines in muscle tissue. No fish with low contamination, for example with a PCB 153 concentration below the detection limit, were caught in that area. In these mullet we observed a negative correlation between contaminant concentration and MA area. The same could be found in flounder when liver tissue was analysed instead of muscle tissue. Also, in that case, concentrations of organochlorines were very high (e.g. HCB was 100 times higher than in muscle tissue). In rabbitfish from the Red Sea, in contrast, fish with PCB concentrations below the detection limit were also found. In these fish, MA area and organochlorine contamination were positively correlated (Broeg, personal observation). It can be assumed that, at the onset of pollution, a decrease in MA-AP is counteracted by building up larger MAs in the liver. A similar phenomenon is known in humans with chronic granulomatous disease. In these patients, a suppressed phagocyte activity is accompanied by a formation of granuloma, built up by 


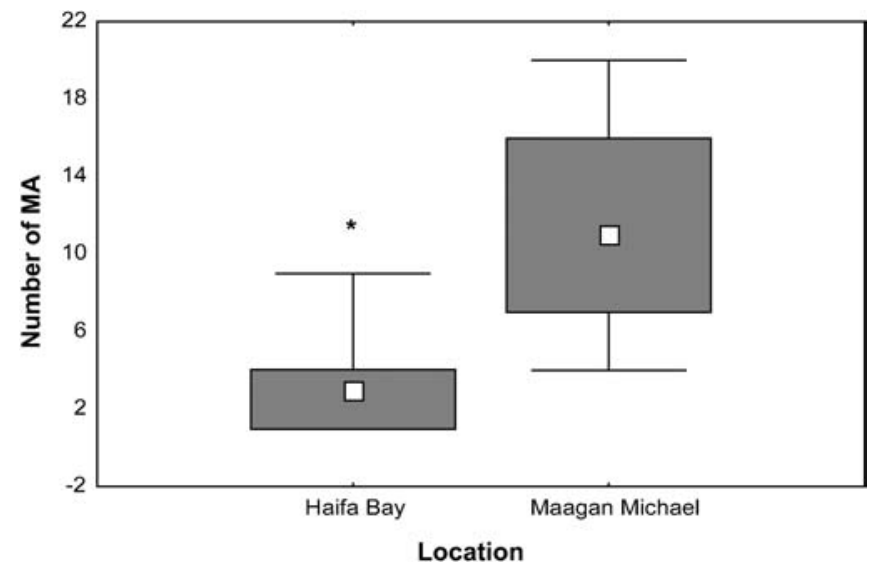

Fig. 9 Numbers of MA per $\mathrm{mm}^{2}$ liver tissue in mullets from two differently polluted locations in the Mediterranean Sea (three campaigns, $n=110$ )

a high number of phagocytes (Curnutte et al. 1976). In the present study, fish which are heavily contaminated may have lost the ability to compensate for a decreased MAAP activity by the formation of larger aggregates. This hypothesis is also supported by the finding that the number of MA was significantly decreased in fish from polluted areas (Fig. 9). In North Sea flounder, we found both heavily polluted animals and also fish with no detectable organochlorine concentration in the muscle. Even in the most polluted location, in the mouth of the River Elbe, flounder had a lower organochlorine load than the mullet in the Mediterranean Sea. In flounder, a positive correlation was found between MA area and contaminant concentration. A moderate contaminant load may lead to an increase in MA area to compensate for the decreased MA-AP activity, and relatively high pollution, on the other hand, may inhibit the generation of large MAs, for example by suppressing macrophage chemotaxis due to the influence of environmental pollution by PCBs, mercury and $\mathrm{HCH}$ as described by other authors (Weeks et al. 1986; Sweet 1999).

To conclude, we consider the results of the present study concerning the morphometry of MA: using only the size of MA and other morphometric parameters is not sufficient for an interpretation of potential immunomodulation under field situation. In addition to MA-AP activity as a measure of MA digestive capacity, MA area might be helpful for the estimation of the grade of immunosuppression. The following hypothesis, rising from the results of the present study, has to be proved in further laboratory experiments:

\begin{tabular}{lllll}
\hline MA-AP & $\downarrow$ & MA area & $\uparrow$ & $\rightarrow$ Moderate effect-compensation \\
MA-AP & $\downarrow$ & MA area & $\downarrow$ & $\rightarrow$ Strong effect-no compensation \\
\hline
\end{tabular}

MA-AP activity gives reliable and consistent results for a quantification of immunomodulation in different fish species when seasonal variation and gender-specific differences are taken into consideration. This new approach to analysing the potential of macrophage activity as an indicator of pollutant-induced injury of the non-specific immune response in fish is easy to apply and, therefore, a potential tool in overall biomarker research.

Acknowledgements This study is part of the MARS 2 project (German-Israeli Co-operation in Marine Sciences), funded by the German Ministry for Education and Science (BMBF).

\section{References}

Aaltonen TM, Jokinen EI, Lappivaara J, Markkula SE, Salo HM, Leppanen H, Lammi R (2000) Effects of primary- and secondary-treated bleached kraft mill effluents on the immune system and physiological parameters of roach. Aquat Toxicol 51:55-67

Alcorn SW, Murra AL, Pascho RJ (2002) Effects of rearing temperature on immune functions in sockeye salmon (Oncorhynchus nerka). Fish Shellfish Immunol 12:303-334

Anderson DP, Zeeman MG (1995) Immunotoxicology in fish. In: Rand GM (ed) Fundamentals of aquatic toxicology: effects, environmental fate and risk assessment, 2 nd edn. Taylor and Francis, Washington DC, USA, pp371-404

Attwood EM, Weich DJ, Oosthuizen JM (1996) The influence of carbon particles on the concentration of acid phosphatase and lysozyme enzymes within alveolar macrophages during the killing and degradation of Mycobacterium bovis. Tuber Lung Dis 77: $341-347$

Baier-Anderson C, Anderson RS (2000) Suppression of superoxide production by chlorothalonil in striped bass (Morone saxatilus) macrophages: the role of cellular sulfhydryls and oxidative stress. Aquat Toxicol 50:85-96

Black CM, Beaman BL, Donovan RM, Goldstein E (1983) Effect of virulent and less virulent strains of Nocardia asteroides on acid phosphatase activity in alveolar and peritoneal macrophages maintained in vitro. J Infect Dis 148:117-124

Bly JE, Clem LW (1991) Temperature-mediated processes in teleost immunity: in vitro immunosuppression induced by in vivo low temperature in channel catfish. Vet Immunol Immunopathol 28:365-377

Bly JE, Clem LW (1992) Temperature and teleost immune functions. Fish Shellfish Immunol 2:159-171

Bols NC, Brubacher JL, Ganassin RC, Lee LEJ (2001) Ecotoxicology and innate immunity in fish. Dev Comp Immunol 25:853-873

Broeg K, Zander S, Diamant A, Körting W, Krüner G, Paperna I, von Westernhagen $H$ (1999) The use of fish metabolic, pathological and parasitological indices in pollution monitoring I. North Sea. Helgol Mar Res 53:171-194

Broeg K, Köhler A, von Westernhagen H (2002) Disorder and recovery of environmental health monitored by means of lysosomal stability in liver of European flounder (Platichthys flesus L.). Mar Environ Res 54:569-573

Chen D, Ainsworth AJ (1991) Effect of temperature on the immune system of channel catfish (Ictalurus punctatus). 2. Adaptation of anterior kidney phagocytes to 10 degree C. Comp Biochem Physiol A 100: 913-918

Chieco P, Jonker A, Melchiorri C, Vanni G, Van Noorden CJF (1994) A user's guide for avoiding errors in absorbance image cytometry: a review with original experimental observations. Histochem J 26:1-19

Crespo S, Grau A, Padros F (1994) The intensive culture of 0-group amberjack in the western Mediterranean is compromised by disease problems. Aquacult Int 2:262-265

Curnutte JT, Whitten DM, Babior BM (1976) Defective superoxide production by granulocytes from patients with chronic granulomatous disease. N Engl J Med 290:593-597 
Dalela RC, Rani S, Verma SR (1980) Physiological stress induced by sublethal concentrations of phenol and pentachlorophenol in Notopterus notopterus: hepatic acid and alkaline phosphatases and succinic dehydrogenase. Environ Pollut 21A:3-8

Dethlefsen V, Lang T, Koeves P (2000) Regional patterns in prevalence of principal external diseases of dab Limanda limanda in the North Sea and adjacent areas 1992-1997. Dis Aquat Org 42:119-132

Drewa G, Dabrowska T, Zbytniewski Z, Patuch F (1979) Effect of crude oil and detergent 'SOLO' on the activity of some hydrolases in hemolymph of crab Rhithropanopeus harrisi. Pol Arch Hydrobiol 26:205-211

Ellis AE (2001) Innate host defence mechanisms of fish against viruses and bacteria. Dev Comp Immunol 25:827-839

Fatima M, Ahmad I, Siddiqui R, Raisuddin S (2001) Paper and pulp mill effluent-induced immunotoxicity in freshwater fish Channa punctatus (Bloch). Arch Environ Contam Toxicol 40:271276

Fletcher TC (1982) Non-specific defence mechanisms of fish. Dev Comp Immunol [Suppl 2]:123-132

Goerke H, Weber K (2001) Species-specific elimination of polychlorinated biphenyls in estuarine animals and its impact on residue patterns. Mar Environ Res 51:131-149

Grinwis GCM, Boonstra A, van den Brandhof E-J, Dormans JAMA, Engelsma M, Kuiper RV, van Loveren H, Wester PW, Vaal MA, Vethaak AD, Vos JG (1998) Short-term toxicity of bis(tri- $n$-butyltin)oxide in flounder (Platichthys flesus): pathology and immune function. Aquat Toxicol 42:15-36

Guiney PD, Melancon MJ Jr, Lech JJ, Peterson RE (1979) Effects of egg and sperm maturation and spawning on the distribution and elimination of a polychlorinated biphenyl in rainbow trout (Salmo gairdneri). Toxicol Appl Pharmacol 47:261-272

Gupta S (1987) Physiological stress induced by sublethal concentrations of phenolic compounds in Notopterus notopterus: measurement of hydrolytic enzymes. Environ Res 42:304-311

Gupta AK, Rajbanshi VK (1985) Histoenzymological study on the toxicity of copper and cadmium in the liver and kidney of Heteropneustes fossilis (Bloch). Int J Acad Ichthyol 6:5-10

Hardie LJ, Fletcher TC, Secombes CJ (1994) Effect of temperature on macrophage activation and the production of macrophage activating factor by rainbow trout (Oncorhynchus mykiss) leucocytes. Dev Comp Immunol 18:57-66

Hayman JR, Bly JE, Levine RP, Lobb CJ (1992) Complement deficiencies in channel catfish (Ictalurus punctatus) associated with temperature and seasonal mortality. Fish Shellfish Immunol 2:183-192

Lakshmi R, Kundu R, Thomas E, Mansuri AP (1991) Mercuric chloride induced inhibition of acid and alkaline phosphatase activity in the kidney of mudskipper, Boleophthalmus dentatus. Acta Hydrochim Hydrobiol 19:341-344

Luebke RW, Hodson PV, Faisal M, Ross PS, Grasman KA, Zelikoff J (1997) Aquatic pollution-induced immunotoxicity in wildlife species. Fundam Appl Toxicol 37:1-15

Luster M I, Munson AE, Thomas PT, Holsapple MP, Fenters JD, White KL, Lauer LD, Germolec DR, Rosenthal GJ, Dean JH
(1988) Development of a testing battery to assess chemicalinduced immunotoxicity: national toxicology programs guidelines for immunotoxicity evaluation in mice. Fundam Appl Toxicol 10:2-19

Niimi AJ, Oliver BG (1983) Biological half-lives of polychlorinated biphenyl (PCB) congeners in whole fish and muscle of rainbow trout (Salmo gairdneri). Can J Fish Aquat Sci 40:1388-1394

Panara F (1997) Acid phosphatases of Esox lucius: tissue distribution and partial characterization. J Fish Biol 51:275-283

Rashatwar S, Ilyas R (1983) Effect of chronic herbicide intoxication on in vivo activities of certain enzymes in the liver of freshwater fish Nemachelius denisonii (Day). Toxicol Lett $16: 249-252$

Sindermann CJ (1996) Ocean pollution: effects on living resources and humans. CRC Press, Boca Raton, Fla., USA

Sweet LI (1999) Impacts of mercury, polychlorinated biphenyl, and hexachlorocyclohexane isomer contaminants on human and fish immune system cells. Diss Abst Int Pt B-Sci \& Eng 60:2049

Tatner MF, Manning MJ (1985) The ontogenetic development of the reticulo-endothelial system in the rainbow trout, Salmo gairdneri Richardson. J Fish Dis 8(2):189-195

Tort L, Padros F, Rotllant J, Crespo S (1998) Winter syndrome in the gilthead sea bream Sparus aurata. Immunological and histopathological features. Fish Shellfish Immunol 8:37-47

Vaddi K, Wei CI (1991) Effect of ammonium metavanadate on the mouse peritoneal macrophage lysosomal enzymes. J Toxicol Environ Health 33:65-78

Vethaak AD (1993) Fish disease and marine pollution: a case study of the flounder (Platichthys flesus) in Dutch coastal and estuarine waters. PhD thesis, Amsterdam

Vethaak AD, Jol JG (1996) Diseases of flounder (Platichthys flesus) in Dutch coastal and estuarine waters with particular reference to environmental stress factors, Part 1. Epizoötiology of gross lesions. Dis Aquat Org 26:81-97

Weeks BA, Warinner JE, Mason PL, McGinnis DS (1986) Influence of toxic chemicals on the chemotactic response of fish macrophages. J Fish Biol 28:653-658

Westernhagen H von, Cameron P, Janssen D, Kerstan M (1995) Age and size dependent chlorinated hydrocarbon concentrations in marine teleosts. Mar Pollut Bull 30:655-659

Zapata AG, Varas A, Torroba M (1992) Seasonal variations in the immune system of lower vertebrates. Immunol Today 13:142147

Zelikoff JT (1993) Metal pollution-induced immunomodulation in fish. Annu Rev Fish Dis 3:305-325

Zelikoff JT, Enane NA, Bowser D, Squibb KS, Frenkel K (1991) Development of fish peritoneal macrophages as a model for higher vertebrates in immunotoxicological studies. I. Characterization of trout macrophage morphological, functional, and biochemical properties. Fundam Appl Toxicol 16:576-89 